\title{
PROGRAMA DE TRAINEE \\ Capacitação e inclusão de novos membros no ambiente do PET
}

Lorena N. de Macena ${ }^{1}$; Matheus L. de Barros ${ }^{1}$; Álvaro T. de Paiva ${ }^{1}$; Amanda

A. Benjamim¹; Gabriela R. Contreira1; Lorena G. Carneiro'; Maria Luisa C.

Duran ${ }^{1}$; Valdivino C. T. Júnior ${ }^{1}$; Vinícius C. Santos ${ }^{1}$; Fabiana S. de Arruda ${ }^{2}$.

${ }^{1}$ Estudante de Engenharia Civil na Universidade de Brasília

${ }^{2}$ Tutora do PET Engenharia Civil na Universidade de Brasília

PET Engenharia Civil, Universidade de Brasília, Brasília, Distrito Federal.

Palavras-chave: Organização Interna; Processo Seletivo; Inovação.

\section{Introdução}

O trainee é considerado como aquele em treinamento, em organizações e instituições. Frente à rotatividade de alunos nos grupos do Programa de Educação Tutorial (PET), o Programa de Trainee (PDT) desponta como ferramenta para a gestão de conhecimento de forma eficiente, de modo que os processos sejam executados de maneira padronizada ao longo do tempo, além de incentivar a busca pela inovação, ao promover a otimização de atividades e ao atuar na resolução de problemas. Aplicado ao PET, os PDTs também fomentam a interação entre os envolvidos, de maneira a fortalecer o grupo, ao mesmo tempo, que trazem desenvolvimento individual pela capacitação em habilidades técnicas e prática de trabalho em equipe.

Segundo o Manual de Orientações Básicas (MOB), os grupos PET visam ampliar as experiências dos estudantes participantes, de modo a enriquecer 0 desenvolvimento acadêmico e contribuir para a formação de cidadãos. A prática do Programa de Trainee confere um caráter inovador para o PET, ao permitir a gestão de mudança pela rotatividade de alunos, em acordo com as diretrizes do MOB. No PET Engenharia Civil da Universidade de Brasília (UnB), o processo seletivo de 2018 foi constituído de quatro etapas, sendo todas de caráter eliminatório; 1) fase escrita; 2) fase de dinâmicas de grupo; 3) fase de entrevistas; e 4) PDT. 
O objetivo principal deste trabalho é apresentar os resultados obtidos no Programa de Trainee realizado pelo PET Engenharia Civil da Universidade de Brasília (UnB), assim como, os dados da pesquisa de satisfação. Os objetivos secundários são destacar a importância do PDT como ferramenta de gestão de inovação e de conhecimento, além de fomentar a prática nos grupos PET.

\section{Metodologia}

O Programa de Trainee (PDT) foi separado em duas vertentes: atividades de formação e atividades de desenvolvimento. As atividades de formação foram compostas por cursos e oficinas de temas variados, com o fim de capacitar os trainees quanto às habilidades comportamentais e às habilidades técnicas, relevantes para a execução das atividades do grupo. Dentre os assuntos abordados, destacam-se (1) organização interna do PET Engenharia Civil da UnB; (2) apresentação da estrutura do PET e do Manual de Orientações Básicas (MOB); (3) curso edição e manutenção de websites; (4) curso de edição de imagens no photoshop; (5) oficina sobre trabalho em equipe, organizado em parceria com o PET Psicologia da UnB; e (6) oficina sobre gestão do tempo. Adotou-se a metodologia da tutoria rotativa, conforme enunciado por Gonzaga et al. (2018), que consiste em alternar os responsáveis por coordenar as atividades. Assim, os cursos e oficinas foram ministrados por diferentes petianos (responsáveis), que revezavam entre si de acordo com disponibilidade de horários e conhecimento no assunto em questão. Esta prática evitou que os membros do grupo ficassem sobrecarregados e trouxe maior dinamicidade às atividades de formação.

As atividades de desenvolvimento foram definidas de modo a inserir os trainees no ambiente do programa. Desta maneira, foram identificadas as principais carências de projetos com o intuito de possibilitar a resolução, por parte dos trainees, de desafios reais enfrentados pelo grupo. Uma dupla de petianos foi destinada para gerenciar cada atividade, de modo a favorecer a integração com os trainees e a diversidade de opiniões. O acompanhamento da execução era realizado através de reuniões semanais entre os petianos responsáveis e os trainees. Foram elencadas cinco atividades de desenvolvimento de acordo com a Tabela 1, sendo três específicas para apenas um grupo, enquanto que as duas 
restantes envolveram todos os participantes. No total foram nove candidatos no PDT, divididos em grupos de três alunos. O número de atividades e a distribuição dos trainees nos grupos mostrou-se satisfatória ao caso em questão, de modo que deve ser readequada conforme a complexidade dos projetos propostos e 0 número de candidatos.

Tabela 1: Atividades de desenvolvimento

\begin{tabular}{|c|c|c|}
\hline Grupos & Descrição da Atividade & Justificativa da Atividade \\
\hline $\begin{array}{c}\text { Grupo 1 } \\
\text { (3 trainees) }\end{array}$ & $\begin{array}{c}\text { Atualização do manual de identidade } \\
\text { visual (MIV) do PET. }\end{array}$ & $\begin{array}{c}\text { Ajustar os padrões de publicações nas } \\
\text { páginas de mídias sociais. }\end{array}$ \\
\hline $\begin{array}{c}\text { Grupo 2 } \\
\text { (3 trainees) }\end{array}$ & $\begin{array}{c}\text { Gestão de Patrimônio: Mapeamento } \\
\text { do patrimônio do grupo. }\end{array}$ & $\begin{array}{c}\text { Facilitar a identificação e aquisição de } \\
\text { bens do PET. }\end{array}$ \\
\hline $\begin{array}{c}\text { Grupo 3 } \\
\text { (3 trainees) }\end{array}$ & $\begin{array}{c}\text { Proposta de um novo projeto de } \\
\text { competição a ser organizada pelo } \\
\text { PET em 2019. }\end{array}$ & $\begin{array}{c}\text { Estruturar uma competição com alunos } \\
\text { de diferentes disciplinas, com o intuito } \\
\text { de favorecer o maior aprendizado } \\
\text { destes. }\end{array}$ \\
\hline $\begin{array}{c}\text { Todos os } \\
\text { Grupos }\end{array}$ & $\begin{array}{c}\text { Novo Projeto: Proposta de execução } \\
\text { de um novo projeto a ser } \\
\text { desenvolvido pelo PET em 2019. }\end{array}$ & $\begin{array}{c}\text { Trazer inovação para as atividades do } \\
\text { grupo, de modo a ampliar a experiência } \\
\text { no programa. }\end{array}$ \\
\hline $\begin{array}{c}\text { Todos os } \\
\text { Grupos }\end{array}$ & $\begin{array}{c}\text { Redesenho da SENC: Proposta de } \\
\text { Selhorias da organização da anual } \\
\text { Semana de Engenharia Civil e } \\
\text { Ambiental (SENC). }\end{array}$ & $\begin{array}{c}\text { Otimizar os processos na organização } \\
\text { da SENC e identificar os principais } \\
\text { problemas enfrentados. }\end{array}$ \\
\hline
\end{tabular}

Fonte: Elaborado pelos autores.

Com a definição das atividades, os candidatos tiveram um período de sete semanas para o desenvolvimento das tarefas. De modo que, no último dia, cada grupo apresentou os resultados obtidos aos petianos, durante 15 minutos. A partir disto, foi realizada a avaliação de desempenho dos trainees e um formulário de satisfação foi enviado para os candidatos, com o intuito de saber sua opinião e considerações a respeito das atividades propostas. Uma seção foi destinada para a autoavaliação de desempenho e outra para a organização do PDT, para mensurar o desenvolvimento individual e abrir um espaço para sugestões de melhorias para futuros processos seletivos. Além disto, todos os candidatos avaliaram-se entre si quanto a habilidades importantes para o grupo, como trabalho em equipe e comunicação. 


\section{Resultados e discussão}

Finalizado o Programa de Trainee (PDT), obtiveram-se diversos arquivos e documentos referentes ao detalhamento de cada atividade proposta de acordo com a Tabela 1 da seção de Metodologia.

Manual de Identidade Visual (MIV) do grupo foi reformulado, trazendo aspectos como o estabelecimento de uma paleta de cores padronizada a ser utilizada em conteúdos visuais relacionados ao PET, a disposição dos elementos do logotipo e as proporções a serem respeitadas. Indicou também a fonte a ser utilizada nos documentos e postagens do grupo. A Figura 1 apresenta a padronização do logotipo do PET Engenharia Civil.

Figura 1: Logotipo do PET Engenharia Civil da UnB.

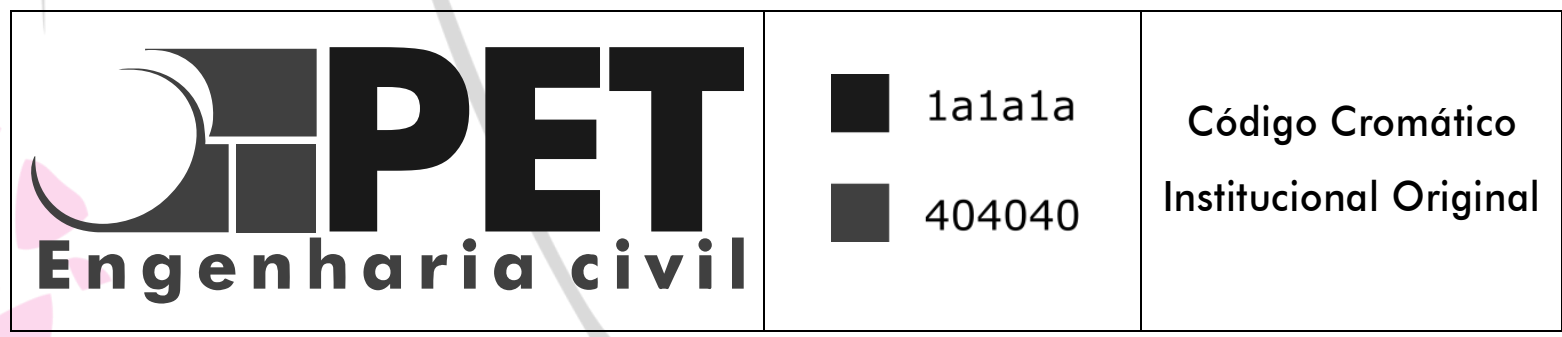

Fonte: Elaborado pelos autores.

No que tange à gestão de patrimônio, foi realizado um levantamento de todos os bens da sala do PET e seu posterior catálogo, com o fim de aprimorar a organização e controle destes itens. Ademais, foram elaboradas propostas de layout da sala, para valorizar o ambiente e promover o melhor uso do espaço.

Foi desenvolvida também a proposta de uma nova competição a ser implementada, a CONCREPET, que consiste na realização de desafios de esferas de concreto, produzidas pelas equipes participantes. Criou-se um edital protótipo e um cronograma para a atividade. O objetivo desta competição é contribuir com o aprendizado dos alunos das disciplinas de materiais de construção e promover a integração dos participantes.

Além disso, o desafio de criar novas atividades ao PET trouxe como resultado dois projetos que abarcam a questão social. O primeiro deles, a Gincana 
Solidária, tem como meta arrecadar roupas, brinquedos e alimentos, para subsequente doação para instituições carentes, bem como aproximar o PET dos calouros da Engenharia Civil. Propôs-se que os calouros sejam convidados a angariar os itens a serem doados e, em datas marcadas, seja organizada uma gincana e posteriormente a entrega das arrecadações. A segunda proposta, o Projeto Reformar, consiste na promoção de uma ação social de reformas simples feitas por voluntários, em locais que beneficiem a comunidade, como, por exemplo, escolas públicas. É necessário um planejamento detalhado de todas as etapas, como a escolha do local, inscrição dos voluntários, orçamento e serviços a serem prestados. Ressalta-se também que foi sugerido a realização de cursos para capacitar aqueles que farão a reforma, a depender do trabalho proposto.

Em relação ao Redesenho da Semana de Engenharia Civil e Ambiental (SENC), foram elencados os problemas recorrentes de edições anteriores, sendo proposto um conjunto de soluções inovadoras. Entre as dificuldades levantadas, destacam-se falta de automatização de atividades, entraves em estabelecer parcerias com organizações não-governamentais (ONGs) e empresas, assim como, ausência de registros de edições passadas que permitem um melhor planejamento. Desta forma, propuseram-se soluções para os tópicos discutidos e, a partir destas, foram concebidos protótipos com detalhamentos da execução.

Através do formulário de satisfação preenchido pelos nove candidatos quanto aos parâmetros de organização do PDT, adequação das Atividades Propostas e nível de Aprendizado em uma escala de 1 a 5, sendo 1 "péssimo" e 5 "excelente", obtiveram-se os resultados a seguir. Não houveram notas de 1 a 3 , indicando a boa aceitação do PDT pelos candidatos nas três variáveis pesquisadas. No caso das Atividades Propostas e o Aprendizado, 66,67\% dos candidatos apontaram estes parâmetros com a nota máxima. Enquanto que $66,67 \%$ apontaram a nota 4 para a organização do PDT.

Para edições futuras, os candidatos recomendaram um cronograma mais robusto com datas bem espaçadas, com o intuito de evitar a concentração de atividades e o choque com épocas de provas de disciplinas. Foi sugerido que 
houvessem mais cursos e oficinas, e que estes fossem realizados anteriormente ao início das atividades de desenvolvimento, de modo que pudessem contribuir na execução das tarefas do PDT.

\section{Conclusões}

Cada participante teve a oportunidade de conhecer mais sobre O PET Engenharia Civil da UnB, sobre suas atividades e como estas são organizadas, o trabalho em equipe e os pilares do Programa de Educação Tutorial. A proposta de tarefas muito similares às atividades atribuídas ao grupo e a inclusão dos candidatos à rotina de reuniões semanais foram fatores preponderantes para alcançar bons resultados, de modo a garantir a integração e a disciplina dos participantes. Deste modo, pode-se considerar como efetivo o trabalho realizado no período de treinamento, em que foi possível validar a importância da prática tanto para inserir o trainee no contexto do PET, quanto para promover a inovação, por meio da estruturação de novas ideias e resolução de problemas. O PDT se mostrou adequado como parte do processo seletivo de alunos para o PET, por apresentar atividades coerentes com a rotina do grupo e contribuir com o desenvolvimento individual de cada candidato. Pelo fato de ter sido a primeira edição realizada pelo PET Engenharia Civil da UnB, a organização pode ser aperfeiçoada de acordo com as sugestões levantadas pelos respondentes do formulário e pelos próprios petianos.

\section{Referências}

GONZAGA, C. M. G. et al. TUTORIA ROTATIVA COMO FORMA DE ENSINO E APRENDIZAGEM DE SOFTWARE PARA ENGENHARIA CIVIL. V CONPET - Congresso Nacional de Grupos PET Engenharia Civil, Ouro Preto, Minas Gerais, 2018.

Programa de Educação Tutorial. Manual de Orientações Básicas - PET/2002. Disponível em: <http://portal.mec.gov.br/pet/manual-de-orientacoes> Acesso em janeiro de 2019. 